\title{
BCL-2 family members and the mitochondria in apoptosis
}

\author{
Atan Gross, ${ }^{1}$ James M. McDonnell, ${ }^{2}$ and Stanley J. Korsmeyer ${ }^{1,3}$ \\ ${ }^{1}$ Departments of Pathology and Medicine, Dana-Farber Cancer Institute, Harvard Medical School, Boston, Massachusetts \\ 02115 USA; $^{2}$ The Rockefeller University, New York, New York 10021 USA
}

\section{The BCL-2 family}

A variety of physiological death signals, as well as pathological cellular insults, trigger the genetically programmed pathway of apoptosis (Vaux and Korsmeyer 1999|. Apoptosis manifests in two major execution programs downstream of the death signal: the caspase pathway and organelle dysfunction, of which mitochondrial dysfunction is the best characterized (for reviews, see Green and Reed 1998; Thornberry and Lazebnik 1998). As the BCL-2 family members reside upstream of irreversible cellular damage and focus much of their efforts at the level of mitochondria, they play a pivotal role in deciding whether a cell will live or die (Fig. 1).

The founder of this family, the $B C L-2$ proto-oncogene, was discovered at the chromosomal breakpoint of $\mathrm{t}(14 ; 18)$ bearing human B-cell lymphomas. The BCL-2 family of proteins has expanded significantly and includes both pro- as well as anti-apoptotic molecules. Indeed, the ratio between these two subsets helps determine, in part, the susceptibility of cells to a death signal (Oltvai et al. 1993) (Fig. 1). An additional characteristic of the members of this family is their frequent ability to form homo- as well as heterodimers, suggesting neutralizing competition between these proteins. A further characteristic of probable functional significance is their ability to become integral membrane proteins.

BCL-2 family members possess up to four conserved BCL-2 homology (BH) domains designated $\mathrm{BH} 1, \mathrm{BH} 2$, $\mathrm{BH} 3$, and $\mathrm{BH} 4$, which correspond to $\alpha$-helical segments (Adams and Cory 1998; Kelekar and Thompson 1998; Reed 1998) (Fig. 2). Many of the anti-apoptotic members display sequence conservation in all four domains. The pro-apoptotic molecules frequently display less sequence conservation of the first $\alpha$-helical segment, BH4. Deletion and mutagenesis studies argue that the amphipathic $\alpha$-helical BH3 domain serves as a critical death domain in the pro-apoptotic members. This concept is supported by an emerging subset of "BH3-domain-only" members who display sequence homology only within the $\mathrm{BH} 3$ domain and to date are all pro-apoptotic. However, the three-dimensional structure of at least one $\mathrm{BH} 3$-domain-

${ }^{3}$ Corresponding author.

E-MAIL stanley_korsmeyer@dfci.harvard.edu; FAX (617) 632-6401. only molecule, BID, demonstrates a very similar overall $\alpha$-helical content to the anti-apoptotic molecule BCL-X $\mathrm{X}_{\mathrm{L}}$ (Chou et al. 1999; McDonnell et al. 1999). Many BCL-2 family members also contain a carboxy-terminal hydrophobic domain, which in the case of BCL-2 is essential for its targeting to membranes such as the mitochondrial outer membrane (Nguyen et al. 1993).

\section{Upstream of mitochondria: activation of BCL-2 family members}

A considerable portion of the pro- versus anti-apoptotic BCL-2 members localize to separate subcellular compartments in the absence of a death signal. Anti-apoptotic members are initially integral membrane proteins found in the mitochondria, endoplasmic reticulum (ER), or nuclear membrane (Hockenbery et al. 1990; Krajewski et al. 1993; de Jong et al. 1994; Zhu et al. 1996). In contrast, a substantial fraction of the pro-apoptotic members localize to cytosol or cytoskeleton prior to a death signal (Hsu et al. 1997; Gross et al. 1998; Puthalakath et al. 1999|. Following a death signal, the pro-apoptotic members that have been examined to date undergo a conformational change that enables them to target and integrate into membranes, especially the mitochondrial outer membrane. One model that we will explore holds that anti-apoptotic BCL-2 molecules are "guarding the mitochondrial gate" from the pro-apoptotic BCL-2 members that "gain access" following a death signal.

\section{Post-translational modifications determine active/inactive conformations}

\section{Dimerization}

Activation of the pro-apoptotic molecule BAX appears to involve subcellular translocation and dimerization. In viable cells a substantial portion of BAX is monomeric and found either in the cytosol or loosely attached to membranes. Following a death stimulus, cytosolic and monomeric BAX translocates to the mitochondria where it becomes an integral membrane protein and cross-linkable as a homodimer (Wolter et al. 1997; Gross et al. 1998) (Fig. 3). Experiments using an FK1012 binding pro- 


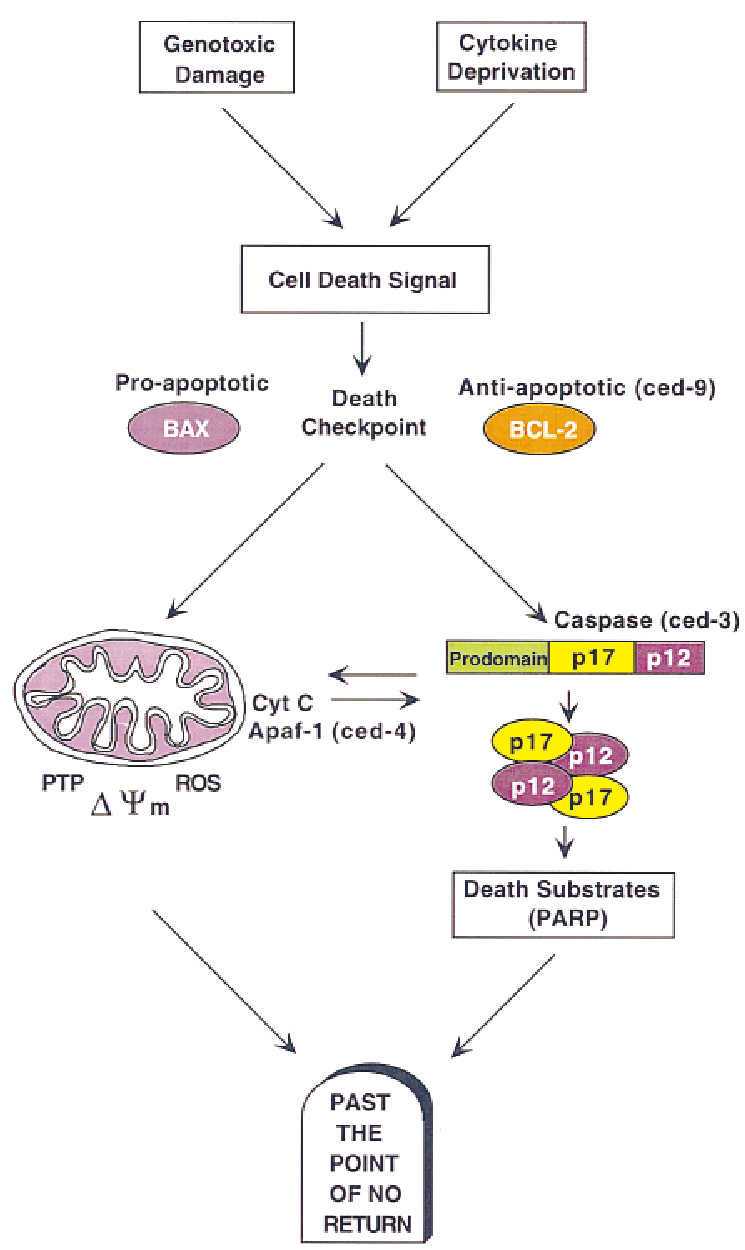

Figure 1. Schematic model of mammalian cell death pathway. A major checkpoint in the common portion of this pathway is the ratio of pro-apoptotic (BAX) to anti-apoptotic (BCL-2) members. Downstream of this checkpoint are two major execution programs: the caspase pathway and mitochondria dysfunction. Mitochondrial dysfunction includes a change in the mitochondrial membrane potential $(\Delta \Psi \mathrm{m})$, production of reactive oxygen species (ROS), opening of the permeability transition pore (PTP), and the release of the intermembrane space protein, cytochrome $c$ (Cyt c). Released cytochrome $c$ activates Apaf-1, which in turn activates a downstream caspase program. Activated caspases can also effect the function of mitochondria. Caspases could be activated through Apaf-1/cytochrome $c$ or directly by activation of cell surface death receptors. Caspases (e.g., caspase-3) are activated by two cleavage events that occur between the prodomain and the large subunit (p17) and between the large subunit and the small subunit (p12). The activated caspase, composed of two large and two small subunits, cleaves death substrates (e.g., PARP), which ultimately leads to cell death.

tein (FKBP)-BAX fusion molecule indicated that enforced dimerization by the bivalent ligand FK1012 results in translocation of the dimer to the mitochondria, where it was capable of killing cells despite the presence of survival factor(s) and BCL- $\mathrm{X}_{\mathrm{L}}$. However, it is still uncertain whether the dimerization of BAX normally occurs in the cytosol or is coincident with membrane insertion. Of note, nonionic detergents that might mimic the membrane environment also induce the dimerization of monomeric BAX and other family members (Hsu and Youle 1997). Following death signals, membraneassociated BAX becomes a more integral-membrane protein and alters the exposure of its amino-terminal domain (Goping et al. 1998; Desagher et al. 1999). Using antibodies directed against an amino-terminal epitope, it was demonstrated that alterations of the amino terminus following a death signal were also observed for BAK (Hsu and Youle 1997; Desagher et al. 1999; Griffiths et al. 1999|. Taken together, one model holds that the amino terminus is concealed to keep the molecule in a closed configuration until an activation stimulus results in a conformational change in BAX or BAK that manifests in its release. Consistent with this model, fulllength BAX would only target mitochondria in vitro when in the presence of a cytosol prepared from cells signaled for apoptosis; indeed, removal of the amino-terminal 20 amino acids of BAX enabled its targeting in the absence of an activated cytosol (Goping et al. 1998).

The presence of an anti-apoptotic molecule such as BCL-2 or BCL- $\mathrm{X}_{\mathrm{L}}$ can inhibit the activation of BAX following a death signal (Gross et al. 1998). In contrast to inactive $\mathrm{BAX}$, which is monomeric and in the cytosol or loosely associated with membranes, BCL-2 is an integral membrane protein heavily localized to mitochondria. It is conceivable that the signal for BAX activation ema-

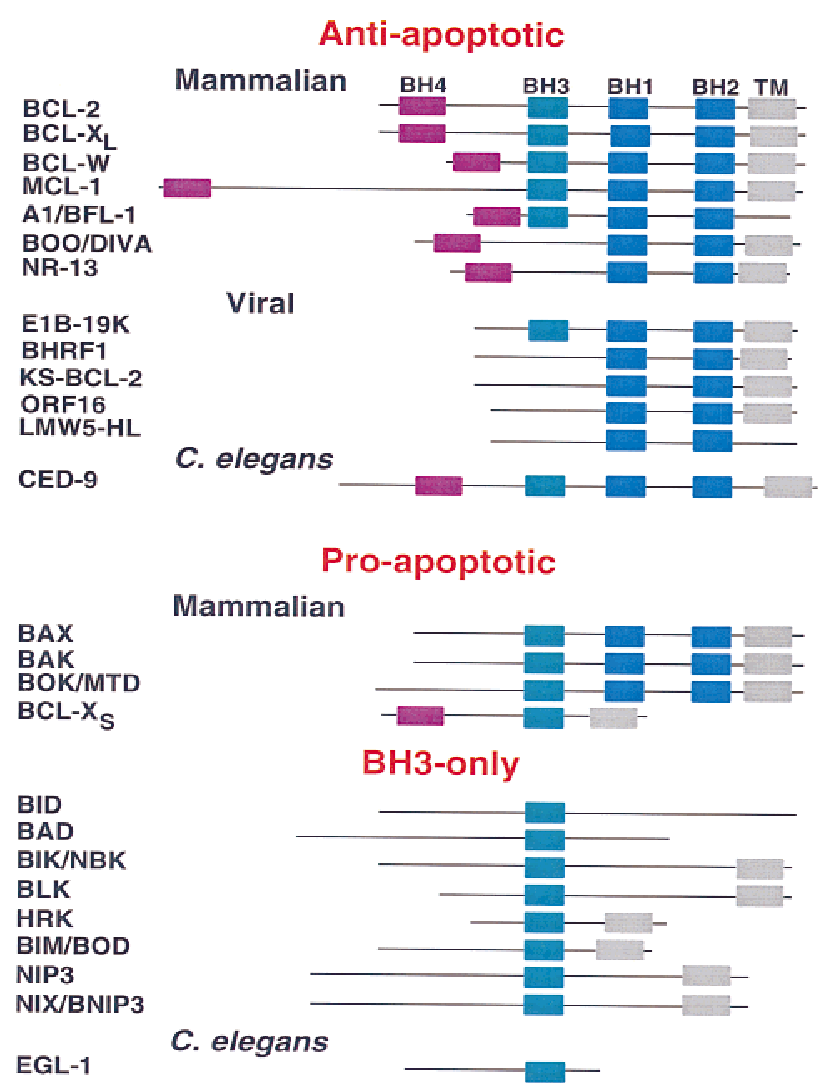

Figure 2. Summary of anti-apoptotic and pro-apoptotic BCL-2 members. BCL-2 homology regions (BH1-4) are denoted as is the carboxy-terminal hydrophobic (TM) domain. 


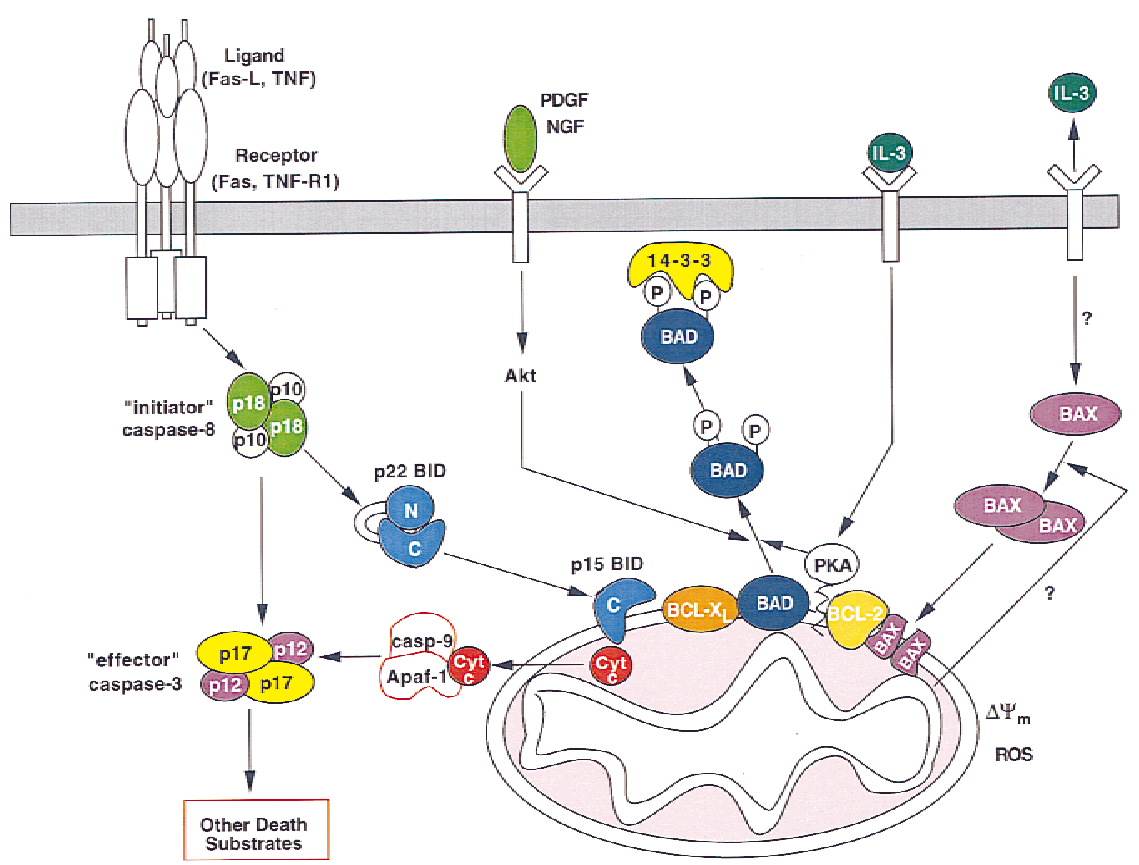

Figure 3. Model of apoptotic and survival signaling pathways involving the BCL-2 members. (Left) Activation of the TNF $\alpha$ / Fas cell surface receptor leads to activation of caspase- 8 . Caspase- 8 cleaves cytosolic p22 BID generating a p15 carboxyterminal fragment that translocates to the mitochondria resulting in the release of cytochrome $c$. Released cytochrome $c$ activates Apaf-1, which in turn activates a downstream caspase program. (Right) A death stimulus (IL-3 deprivation) induces the translocation of BAX to the mitochondria where it is integral membrane and cross-linkable as a homodimer. (Center) Activation of the NGF or PDGF receptors mediates the activation of Akt, resulting in the phosphorylation of BAD at Ser-136. Activation of the IL-3 receptor mediates the activation of the mitochondrial-based PKA holoenzyme, resulting in the phosphorylation of BAD at Ser-112. Phosphorylated $\mathrm{BAD}$ is sequestered to the cytosol by the phosphoserine-binding protein 14-3-3. nates from the mitochondria, although other sources are not excluded.

\section{Translocation}

The BH3-domain-only molecule BIM also translocates to the mitochondria following certain apoptotic stimuli. In healthy cells, BIM molecules are localized to the microtubule-associated dynein motor complex through association with the LC8 dynein light chain (Puthalakath et al. 1999). Following a death signal, LC8 and BIM dissociate from the motor complex and together translocate to the mitochondria. At the mitochondria, BIM is thought to interact with BCL-2 to antagonize its antiapoptotic activity. Questions remain as to whether LC8 is playing an active or passive role in apoptosis. Moreover, it will be important to determine if BIM is an active component of the dynein motor complex and whether its removal damages microtubules.

\section{Phosphorylation}

In the presence of a survival factor, the $\mathrm{BH} 3$-domain-only molecule BAD is phosphorylated on two serine sites (Ser-112 and Ser-136) and sequestered in the cytosol by a 14-3-3 molecule (Fig. 3; Zha et al. 1996c). Following a death signal (e.g., IL-3 deprivation), BAD is dephosphorylated and found in association with $\mathrm{BCL}-\mathrm{X}_{\mathrm{L}}-\mathrm{BCL}-2$. The BH3 domain of BAD appears essential for its interaction with BCL-X $\mathrm{L}_{\mathrm{L}}$-BCL-2 (Kelekar et al. 1997; Ottilie et al. 1997; Zha et al. 1997), and only the nonphosphorylated form of $\mathrm{BAD}$ is capable of binding the BCL- $\mathrm{X}_{\mathrm{L}}$ pocket (Zha et al. 1997). Thus, it appears that phosphorylation regulates the exposure of the $\mathrm{BH} 3$ domain of $\mathrm{BAD}$. This hypothesis would be consistent with the prediction that nonphosphorylated BAD is constitutively active due to the exposure of the hydrophobic face of the $\mathrm{BH} 3$ domain (McDonnell et al. 1999).

To date, several kinases have been shown to phosphorylate and inactivate BAD. Akt/PKB/RAC, a serine/ threonine kinase downstream of phosphatidylinositol 3-kinase, is site-specific for Ser-136 (Datta et al. 1997; del Peso et al. 1997; Blume-Jensen et al. 1998). In addition to BAD, Akt has been demonstrated to phosphorylate and inactivate caspase-9 (Cardone et al. 1998) and the transcription factor FKHRL1 (Brunet et al. 1999), thereby promoting cell survival. Mitochondrial membrane-localized cAMP-dependent protein kinase (PKA) is a BAD Ser112 site-specific kinase (Harada et al. 1999). This molecule represents an attractive subcellulary focused kinase-substrate interaction in which an outer mitochondrial membrane protein, A-kinase anchoring protein (AKAP), tethers the PKA holoenzyme to the organelle where active BAD does its damage. Upon exposure to a survival factor, the localized catalytic subunit of PKA phosphorylates mitochondrial-based $\mathrm{BAD}$, resulting in its inactivation and movement to the cytosol.

BCL-2 is also phosphorylated in vivo and this modification has been demonstrated to effect its anti-apoptotic activity (Haldar et al. 1995; Chang et al. 1997; Ito et al. 1997; Poommipanit et al. 1999). Perhaps phosphorylation within the flexible loop of BCL-2 also induces a conformational change that dictates its function.

\section{Cleavage}

Following TNF $\alpha$ or Fas treatment, BID, a BH3-domainonly molecule is cleaved at its amino terminus (Li et al. 1998; Luo et al. 1998; Gross et al. 1999; Han et al. 1999). Cleavage of cytosolic p22 BID by caspase- 8 generates a 
p15 carboxy-terminal fragment that translocates to the mitochondria (Fig. 3). Truncated p15 BID (tBID) inserts into the membrane and immunodepletion of tBID from subcellular fractions argues that tBID is required for cytochrome $c$ release from the mitochondria. Of note, in the presence of BCL-2 or BCL- $\mathrm{X}_{\mathrm{L}}$ the cleavage and translocation of BID following caspase- 8 activation still occurs (Gross et al. 1999). However, the mitochondrialbased BCL-X $\mathrm{X}_{\mathrm{L}}$ will prevent the release of cytochrome $c$. Yet in certain cell types other aspects of mitochondrial dysfunction still transpire and the cells still die. This suggests that mitochondrial events beyond the release of cytochrome c may be critical to cell death. Overall, the cleavage and translocation of BID may well represent the initial insult to mitochondria in the TNF/Fas pathway, and even be required for the death of certain cell types.

Removal of the amino-terminal domain of BID or BAX enables their targeting to mitochondria, suggesting that these domains are acting as inhibitory domains. Likewise for BIM, the removal of its amino-terminal domain, which keeps it bound to the cytoskeleton and away from the mitochondria, converts it into a more potent killer (Puthalakath et al. 1999).

How might the amino-terminal domain of pro-apoptotic molecules block their activity? Insight into this issue has come from solving the three-dimensional structure of BID (Chou et al. 1999; McDonnell et al. 1999) (Fig. 4). Moreover, this multidimensional nuclear magnetic resonance (NMR) analysis of BID has provided a structural basis for the conformational activation of this family. BID consists of eight $\alpha$ helices, in which the amino-terminal, first $\alpha$ helix makes strong hydrophobic contacts with the third $\alpha$ helix (which contains the $\mathrm{BH} 3$ domain). As a testimony to the strength of this interaction, cleavage of p22 BID by caspase- 8 at Asp59, which resides in a large flexible loop between the second and third $\alpha$ helices, does not result in their immediate dissociation in vitro (Chou et al. 1999). That dissociation does appear to occur in vivo as tBID exists without an associated amino-terminal fragment. Cleavage leads to the exposure of $>200 \AA^{2}$ of previously buried hydrophobic surface and a net charge change from -13 for BID to -4 for tBID (McDonnell et al. 1999). This buried surface includes the hydrophobic face of the $\mathrm{BH} 3$ amphipathic helix and the two central hydrophobic cores, which could potentially cross a bilayer membrane to form a channel. These changes in hydrophobic exposure and surface charge may well contribute to the translocation and integration of tBID into mitochondria, which is among the most strongly negatively charged biological membranes (Darnell et al. 1990). Following translocation and integration into the membrane, tBID can be cleaved at two amino-terminal sites (Asp-75, Asp-98; Gross et al. 1999). Thus, like BAX and BAK, the amino terminus of BID appears to be exposed on the surface of mitochondria. Beyond these striking alterations of the molecule itself, it is also conceivable that other partner proteins might participate in the translocation of BID.

Recently, it has been proposed that BID cooperates with BAX to cause mitochondrial dysfunction (Desagher et al. 1999). Of note, the BH3 domain of BID can bind to the pocket of $\mathrm{BAX}$, and $\mathrm{BH} 3$ mutations that disrupted this interaction also crippled BID's killing capacity (Wang et al. 1996). This suggests several possibilities, among them that BID serves as a chaperone for BAX. Alternatively, BID might induce a conformational change that enables BAX to target and integrate into mitochondrial membranes.

\section{Transcription}

Pro- and anti-apoptotic molecules may be regulated by mechanisms beyond post-translation modification and/ or conformational changes. One prediction is that the constitutively active pro-apoptotic BCL-2 members /see below) will be transcriptionally regulated. To avoid toxicity in healthy cells they would be transcriptionally silent, but in response to selected death stimuli cells would initiate their transcription. The genetic pathway in Caenorhabditis elegans finds transcription factors up-
Figure 4. Comparison of the three-dimensional structures of $\mathrm{BID}$ and $\mathrm{BCL}-\mathrm{X}_{\mathrm{L}}$. Ribbon diagram of the averaged, minimized NMR structures of BID and BCL- $\mathrm{X}_{\mathrm{L}}$. BCL-2 homology (BH) 3 domain (yellow), the central hydrophobic $\alpha$-helices (red), and the remaining $\alpha$ helices (blue) are illustrated. Not shown are large, unstructured flexible loops between residues 31 and 70 in the BID protein and between residues 26 and 76 in the BCL- $\mathrm{X}_{\mathrm{L}}$ protein. This image was prepared using the program SETOR.

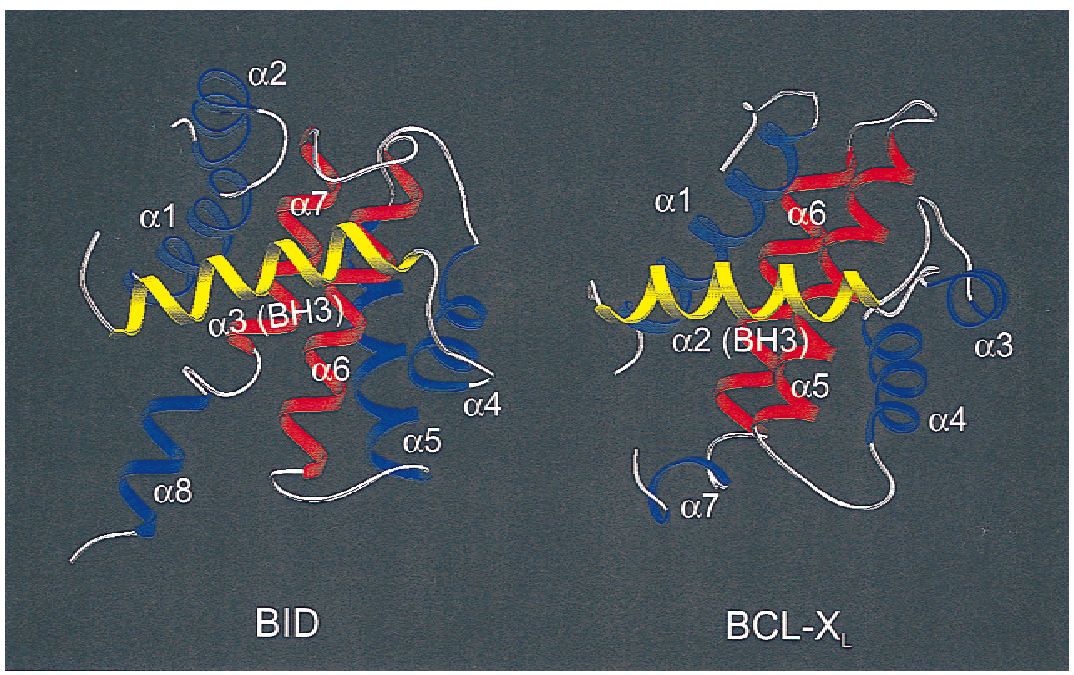


stream of EGL-1, arguing that this BH3-domain-only member will be transcriptionally regulated (Conradt and Horvitz 1998). Moreover, evidence exists that Hrk, which is predicted to be a constitutively active pro-apoptotic molecule, can be up-regulated in response to death stimuli (Inohara et al. 1997). However, transcriptional regulation need not be restricted to this subset of molecules. Indeed, in select settings BAX appears to be transcriptionally responsive to p53 induction (Miyashita and

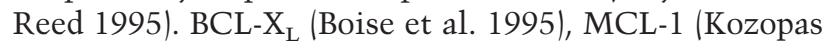
et al. 1993), A-1 (Lin et al. 1993; Grumont et al. 1999; Zong et al. 1999), and, on rare occasions, BCL-2 (von Freeden-Jeffry et al. 1997)—all anti-apoptotic genes-are also transcriptionally responsive.

\section{A structural basis for active and inactive conformers}

One of the most notable characteristic of the BCL-2 family members is their ability to form heterodimers. Such interactions were demonstrated in yeast two-hybrid, in vitro binding assays as well as by coimmunoprecipitation from membrane-solubilized mammalian cells (Oltvai et al. 1993; Sedlak et al. 1995; Zha et al. 1996a). Such interactions were also demonstrated in intact mitochondria in vivo using protein cross-linkers (Gross et al. 1998) or by fluorescent resonance energy transfer (FRET) (Mahajan et al. 1998). The structure of a BCL-X $\mathrm{X}_{\mathrm{L}}$ monomer and a BCL- $\mathrm{X}_{\mathrm{L}}-\mathrm{BAK} \mathrm{BH} 3$ peptide complex revealed that the $\mathrm{BH} 1, \mathrm{BH} 2$, and $\mathrm{BH} 3$ domains of $\mathrm{BCL}-\mathrm{X}_{\mathrm{L}}$ are in close proximity and create a hydrophobic pocket into which the BAK BH3 peptide binds (Muchmore et al. 1996; Sattler et al. 1997). However, in the predicted structure of BAK (based on the BCL- $\mathrm{X}_{\mathrm{L}}$ structure), the hydrophobic face of its $\mathrm{BH} 3$ domain would be buried, making these residues unavailable to interact with BCL$\mathrm{X}_{\mathrm{L}}$ (Sattler et al. 1997). Therefore, a conformational change must occur for BAK to interact with BCL- $\mathrm{X}_{\mathrm{L}}$. Perhaps the conformational changes that were detected in BAX and BAK following death stimuli in cells enable heterodimerization with anti-apoptotic molecules at the mitochondrial membrane. The structure of BID revealed that it does not possess a large hydrophobic pocket consistent with the observation that BID functions as a 'donor' of a BH3 helix but not as an 'acceptor' (McDonnell et al. 1999) (Fig. 5). Despite the very low sequence homology between BID and BCL- $\mathrm{X}_{\mathrm{L}}$ and their opposite effects on apoptosis, their three-dimensional structures are quite similar (Fig. 4). Based on threading analysis, and sequence and secondary structure comparisons, the BCL-2 family members may be subdivided into two conformational subgroups, 'BH3 buried' and the 'BH3 exposed' (McDonnell et al. 1999) (Fig. 5). A leading criterion is whether the $\mathrm{BH} 3$ domain, in particular its hydrophobic face, is available. Perhaps all BCL-2 family members with a buried hydrophobic face of the $\mathrm{BH} 3$ domain are anti-apoptotic or inactive pro-apoptotic molecules. Conversely, other members are predicted to be constitutively active having an exposed $\mathrm{BH} 3$ domain. Following death signals, inactive or even anti-apoptotic molecules can be converted to an active conformation by exposure of the BH3 domain and potentially other hydrophobic surfaces. Based on this comparison, it is likely that BAX is inherently in an inactive conformation but that upon a death stimulus it is modified, resulting in exposure of its amino terminus; the availability of its BH3 domain hydrophobic surface; and its dimerization and translocation to the mitochondrial membrane. Cleavage of the amino terminus of BCL- $\mathrm{X}_{\mathrm{L}}$ or BCL-2 (predicted to expose their $\mathrm{BH} 3$ domain surface) can convert them into pro-apoptotic molecules (Cheng et al. 1997; Clem et al. 1998; Grandgirard et al. 1998).

\section{Subcategories of pro-apoptotics reside upstream or downstream of anti-apoptotics}

Mutational analysis of the $\mathrm{BH} 3$ domain of BAD indicated that BAD mutants that failed to bind BCL-2 or BCL- $\mathrm{X}_{\mathrm{L}}$ no longer promoted cell death (Ottilie et al. 1997; Zha et al. 1997). In concert with these observations, wild-type BAD proved incapable of killing cells bearing a BCL- $\mathrm{X}_{\mathrm{L}}$ pocket mutant that does not allow the BAD BH3 domain to bind within its hydrophobic groove (Kelekar et al. 1997). In contrast, a systematic mutagenesis of the BAX $\mathrm{BH} 3$ region gave a much different answer. For BAX, the retention of killer activity did not correlate with the capacity to form heterodimers in classic binding assays. Instead, the essential characteristics of active BAX mutants was the retention of a hydrophobic face on the $\mathrm{BH} 3$ $\alpha$ helix which retained the capacity to insert as an integral mitochondrial membrane homodimer (Wang et al. 1998).

These data together with insights from the three-dimensional structure of BID argue that the pro-apoptotic BCL-2 members can also be subdivided into two functional subcategories. One set of BH3-domain molecules that lack obvious hydrophobic core $\alpha$ helices, such as

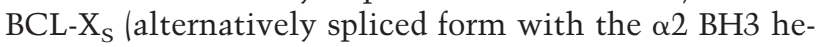
lix but not $\alpha 5$, or $\alpha 6$ hydrophobic helices that appear in BCL-X) and BAD, would serve as upstream death ligands which function by binding to the pocket of BCL-2 or BCL- $\mathrm{X}_{\mathrm{L}}$ to inhibit their anti-apoptotic activity. Egl-1 which is predicted to share only the $\mathrm{BH} 3$ domain and serves as an upstream negative regulator of ced-9 in $C$. elegans, would be similar to $\mathrm{BCL}-\mathrm{X}_{\mathrm{S}}$ and $\mathrm{BAD}$. In contrast, the more full fledged pro-apoptotic members with conserved $\mathrm{BH} 1$ and $\mathrm{BH} 2$ domains corresponding to $\alpha 5$, $\alpha 6$ hydrophobic helical cores can become integral mitochondrial membrane proteins apparently independent of anti-apoptotic members. These molecules could therefore conceivably work downstream or in parallel to BCL-2 or BCL- $\mathrm{X}_{\mathrm{L}}$ as well as binding to them as inhibitors. In parallel, some mutants of $\mathrm{BCL}-\mathrm{X}_{\mathrm{L}}$, that do not bind BAX or BAK can still suppress cell death /Cheng et al. 1996). These observations are all consistent with genetic evidence from mouse transgenic and knockout models that argued BCL-2 and BAX did not require the opposite partner to regulate apoptosis (Knudson and Korsmeyer 1997).

A recent surprise is that $\mathrm{BID}$, a BH3-domain-only, proapoptotic protein with sequence homology restricted to 
Gross et al.

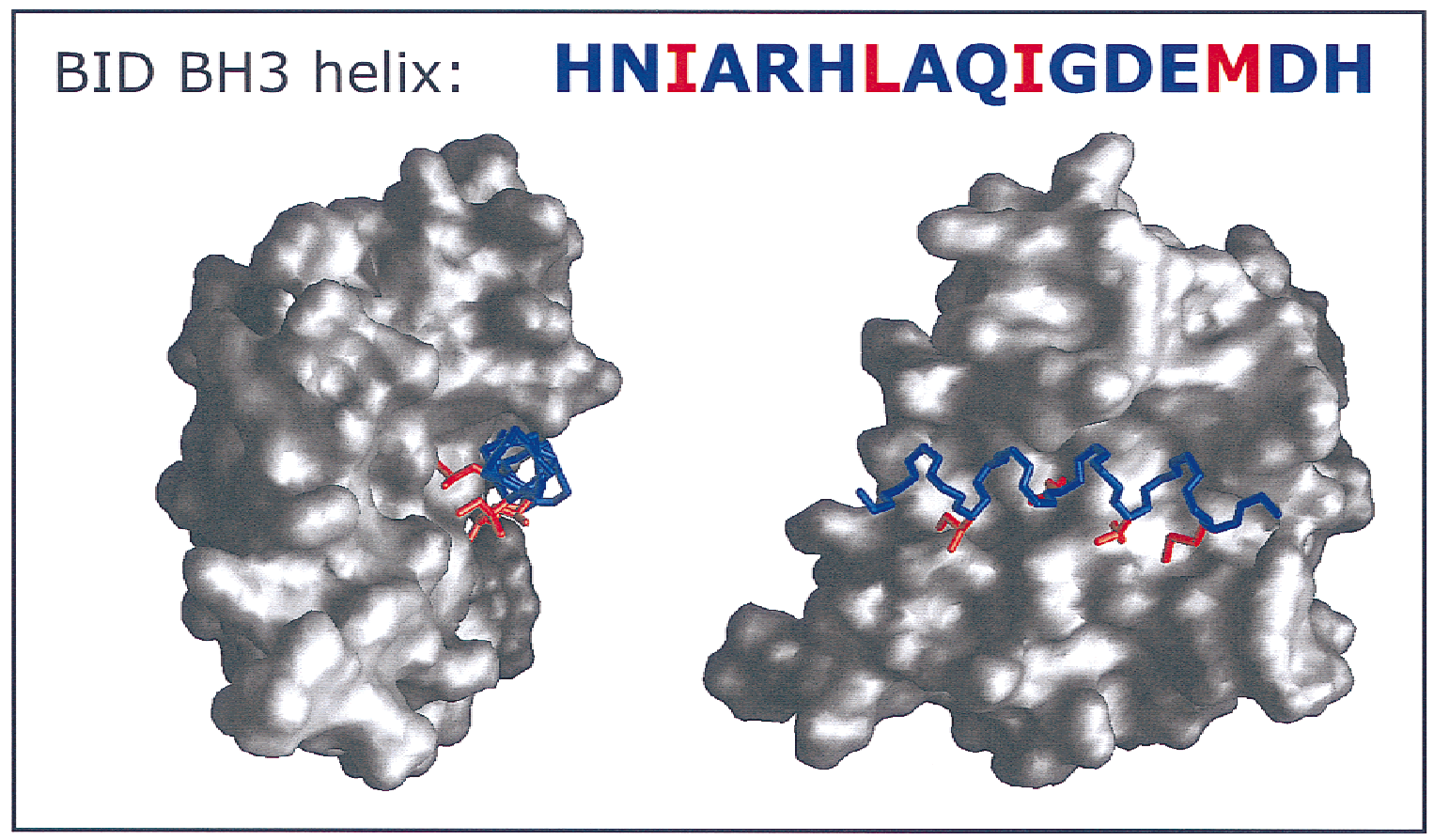

\title{
Predicted structural subsets of the Bcl-2 family
}

\author{
Buried BH3: BID, BCL-X \\ Exposed BH3: tBID, tBCL-2, tBCL-X $\mathrm{X}_{L}$, BCL-X $\mathrm{X}_{S}$, EGL-1, BAD, BIK/NBK, HRK, BIM/BOD, \\ BLK, NIX/BNIP3, NIP3
}

Figure 5. (Top) The hydrophobic BH3 motif is mostly buried in BID. The BID BH3 helix is shown packed against a van der Waals surface of the rest of the BID structure. The side chains of conserved hydrophobic residues of the amphipathic BH3 helix are displayed and colored in red. These residues are largely buried in the BID structure and are inaccessible for intermolecular interactions. The image was prepared using GRASP (Nicholls et al. 1991). (Bottom) Predicted structural subclasses of the BCL-2 family. Based on primary sequence and secondary structure alignments, BCL-2 family members can be grouped into two main structural categories. The 'BH3-buried' family members have a sequence pattern consistent with the conservation of the BID/BCL- $\mathrm{X}_{\mathrm{L}}$ topology and are predicted to have their hydrophobic $\mathrm{BH} 3$ motifs buried. The BH3-buried family members must rely on some mechanism of conformational change to induce their pro-apoptotic activity. The "BH3-exposed" BCL-2 family members are either truncated molecules (tBID, tBCL-2, tBCL- $\mathrm{X}_{\mathrm{L}}, \mathrm{BCL}-\mathrm{X}_{\mathrm{S}}$ ) or family members that have an unrelated tertiary structure; this class of family members seem likely to have their $\mathrm{BH} 3$ domains surface exposed and consequently would be active pro-apoptotic molecules.

nine amino acids in $\mathrm{BH} 3$ domain, also belongs to this latter group and appears to function independent of antiapoptotic members. Structural analysis indicates a remarkable similarity to the classic family members (Fig. 4; Chou et al. 1999; McDonnell et al. 1999) including the presence of two hydrophobic $\alpha$-helical cores. This suggests that BID, which inserts into mitochondrial membranes, can also function downstream of BCL-2 or BCL-X .

\section{The displacement model}

The anti-apoptotic molecules, $\mathrm{BCL}-\mathrm{X}_{\mathrm{L}}$ and the recently cloned BOO/DIVA, have been reported to bind Apaf-1 (apoptotic protease-activating factor-1) and some proapoptotic BCL-2 members have been shown to dissociate this complex (Hu et al. 1998; Pan et al. 1998; Inohara et al. 1998; Song et al. 1999). These observations lead to the hypothesis that one role of pro-apoptotic BCL-2 members is to displace Apaf-1, which might enable activation of caspase-9. This hypothesis is consistent with the genetic pathway in C. elegans in which EGL-1, maps upstream as a negative regulator of CED-9 /Conradt and Horvitz 1998). Moreover, Egl-1 protein will bind CED-9 and CED-9 can also bind CED-4, the Apaf-1 homolog and activator of the downstream caspase CED-3 (Hengartner 1997). Thus, the binding of EGL-1 to CED-9 could dissociate CED-4, releasing it to activate CED-3. Thus, proapoptotic BCL-2 members (especially the BH3-domain only class) which serve as death ligands might also release CED-4-like molecules as well as inhibiting the anti-apoptotic BCL-2 members. 
At the mitochondria: mechanisms of action of pro-/anti-apoptotic molecules

How are death agonists inducing apoptosis and death antagonists inhibiting this process at the level of a membrane? An attractive theory holds that each would form channels or regulate the activity of existing channels in membranes.

This model has its origins in the structural similarity between the BCL- $\mathrm{X}_{\mathrm{L}}$ molecule (in which two central hydrophobic cores are surrounded by four amphipathic helices) and the pore forming helices of bacterial toxins (Muchmore et al. 1996) (Fig. 4). Subsequently it was demonstrated that recombinant $\mathrm{BCL}-\mathrm{X}_{\mathrm{L}}, \mathrm{BCL}-2$, and $\mathrm{BAX}$ can form ion channels in artificial membranes with distinct characteristics (Antonsson et al. 1997; Minn et al. 1997; Schendel et al. 1997,1998; Schlesinger et al. 1997). Perhaps the tendency of BCL-2 family members to form multimers in vitro [e.g., recombinant BAX oligomerizes in solution (Lewis et al. 1998)] and detectable dimers and multimers in vivo (Gross et al. 1998) may relate to their ability to form channels. The surprising similarity in the structure of BID to the BCL- $\mathrm{X}_{\mathrm{L}}$ structure emphasizes the conserved importance of this structure including the two central hydrophobic core helices (Fig. 4).

A major site of activity of the BCL-2 proteins is the mitochondrial membrane (Hockenbery et al. 1990; Green and Kroemer 1998; Zamzami et al. 1998). As discussed above, following a variety of death signals, proapoptotic molecules often translocate to the mitochondria where anti-apoptotic molecules already reside. Downstream of these death signals there are dramatic effects on mitochondrial function, and these alterations can be mimicked by artificially activating or overexpressing pro-apoptotic molecules in cells. Enforced dimerization or inducible expression of BAX or BAK results in altered mitochondrial membrane potential $(\Delta \Psi \mathrm{m})$, production of reactive oxygen species, and in certain settings release of cytochrome $c$, which activates a downstream caspase program (Xiang et al. 1996; McCarthy et al. 1997; Eskes et al. 1998; Gross et al. 1998; Pastorino et al. 1998; Finucane et al. 1999). Inducible expression of p15 tBID in cells has similar effects (Li et al. 1998). In most but not all instances, overexpression of BCL-2 or BCL- $\mathrm{X}_{\mathrm{L}}$ will counter these effects. The complexity of this issue is illustrated by the overexpression of BCL-2 or BCL- $\mathrm{X}_{\mathrm{L}}$, which does not prevent the cleavage and mitochondrial targeting of tBID in response to $\mathrm{TNF} \alpha /$ Fas but does prevent the release of cytochrome $c$. Yet, other damage to mitochondria still occurs and many cell types will still die (Gross et al. 1999). In vitro, both BAX and p15 tBID can cause the release of cytochrome $c$ from mitochondria (Jurgensmeier et al. 1998; Li et al. 1998; Luo et al. 1998; Gross et al. 1999; Han et al. 1999), although p15 tBID is much more effective. One possibility is that BAX or BID may form selective channels for cytochrome $c$ release and potentially other factors from the intermembrane space such as AIF (Susin et al. 1999 b). An alternative role would be for these proteins to regulate the activity of pre-existing channels rather then to form distinct channels themselves. It has been proposed that the altered conductance of existing channels would eventually lead to mitochondrial swelling and the nonspecific rupture of the outer mitochondrial membrane (Vander Heiden et al. 1997). In support of a nonselective mechanism of release, a variety of death signals have been noted to result in the release of adenylate kinase, another intermembrane space protein which has not been shown to be involved in apoptosis (Single et al. 1998).

One theory as to how the BCL-2 family would control the swelling of mitochondria relates to a proposed channel entitled the permeability transition pore (PTP) (Zoratti and Szabo 1995; Zamzami et al. 1998) (Fig. 6). The PTP is a large conductance pore that evolves in mitochondria following necrotic or apoptotic signals. The PTP is permeable to solutes with a molecular mass of $\sim 1500$ daltons when studied in vitro. The PTP is proposed to be composed of or influenced by clustered components of the inner and outer mitochondrial membrane including hexokinase, creatine kinase $(\mathrm{CK})$, voltage-dependant anion channel (VDAC), adenine nucleotide translocator (ANT), the peripheral benzodiazepine receptor $(\mathrm{PBR})$, and even the mitochondrial matrix cyclophilin (CycD) (Fig. 6). Opening of the PTP results in mitochondrial depolarization, uncoupling of oxidative phosphorylation, and swelling of the mitochondria. Some of the effects of atractyloside (Atr), which causes the opening of the PTP, are similar to the effects of recombinant BAX or BAK on purified mitochondria. Mitochondrial effects of BAX could be countered by cyclosporin A (CsA) and bongkrekic acid, both of which induce closure of the PTP, suggesting that BAX may work at least late through opening of the PTP (Shimizu et al. 1998). Direct associations between BAX and ANT (Marzo et al. 1998) or BAX and VDAC (Narita et al. 1998) have been proposed, although none have been detected in the native mitochondrial membrane to date. Alternatively, BCL-2 family members may represent or regulate smaller ion-selective channels. In this respect, it is interesting to note that calcium inhibits the BCL- $\mathrm{X}_{\mathrm{L}}$ channel activity in vitro (Lam et al. 1998). Moreover, the pro-apoptotic Drosophila proteins, Reaper and Grim, have been shown capable of inactivating the voltage-gated $\mathrm{K}^{+}$channels (Avdonin et al. 1998). An understanding of the serial time course of ionic events that occur across the mitochondrial membrane following the targeting of pro-apoptotic molecules may provide further insight into the essential events.

How well can the activities that have been ascribed to BCL-2 family members in vitro be connected with the chain of events that transpire in mitochondria in vivo following a death stimulus? Following a death signal mitochondria initially increase their $\Delta \Psi \mathrm{m}$ followed by a later fall in $\Delta \Psi \mathrm{m}$ (Vander Heiden et al. 1997; Minn et al. 1999). The $\Delta \Psi \mathrm{m}$ is principally achieved by an $\mathrm{H}^{+}$ion gradient generated by electron transport (Fig. 6). This $\mathrm{H}^{+}$ gradient is used by the $\mathrm{F}_{0} \mathrm{~F}_{1}$-ATPase-synthase to synthesize ATP. If the ATP synthase activity were blocked the $\mathrm{H}^{+}$ion gradient might increase manifesting as an 


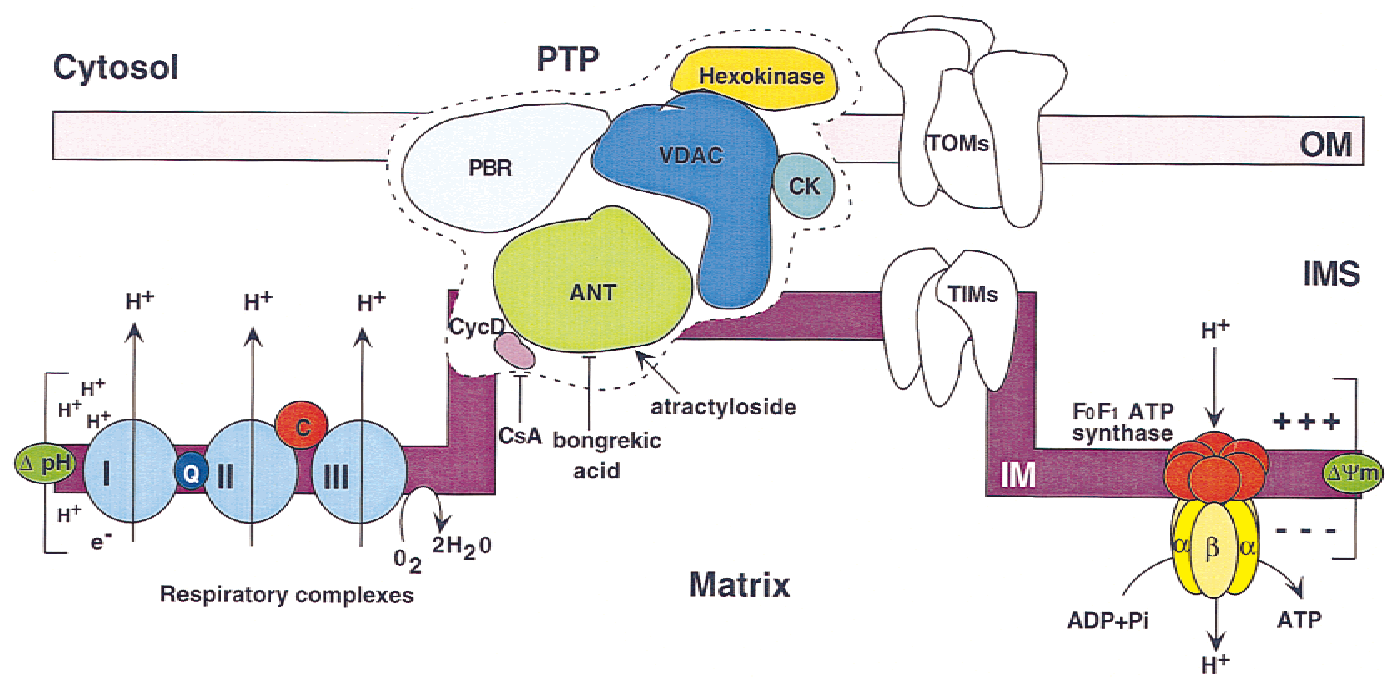

Figure 6. A schematic representation of the respiratory complexes, the $\mathrm{F}_{0} \mathrm{~F}_{1}$-ATP synthase, the translocase of inner membrane/ translocase of outer membrane (TIM/TOM) proteins, and the PTP complex in the mitochondrial inner membrane (IM) and outer membrane (OM). The localization and functions (if known) of the different proteins is depicted. The $\Delta \Psi \mathrm{m}$ is principally achieved by an $\mathrm{H}^{+}$ion gradient generated by electron transport $(\Delta \mathrm{pH})$. This $\mathrm{H}^{+}$gradient is used by the $\mathrm{F}_{0} \mathrm{~F}_{1}$ synthase to synthesize ATP. PTP is proposed to be composed or influenced by clustered components of the inner and outer mitochondrial membrane including hexokinase, creatine kinase (CK), voltage-dependent anion channel (VDAC), adenine nucleotide translocation (ANT), the peripheral benzodiazepine receptor (PBR), and the mitochondrial matrix cyclophilin (CycD). Different agents that induce (arrows) or block opening of the PTP are shown.

increase in $\Delta \Psi \mathrm{m}$. For example, impairment of the $\mathrm{F}_{0} \mathrm{~F}_{1}-$ ATP synthase activity would follow if the Pi or ADP in the matrix became limiting, a direct inhibitor of the $\beta$-subunit existed, $\mathrm{H}^{+}$flow through the $\mathrm{F}_{\mathrm{O}}$ stalk region was blocked or the ATPase activity of this enzyme dominated. In all instances, the $\mathrm{H}^{+}$ion gradient would increase. A comparison with BCL- $\mathrm{X}_{\mathrm{L}}$-protected cells suggests that the reason for the increased $\Delta \Psi \mathrm{m}$ is a decrease in the mitochondrial matrix concentration of ADP (Vander Heiden et al. 1999). This work argues that BCL$\mathrm{X}_{\mathrm{L}}$ helps maintain ADP levels, perhaps by regulating the permeability of VDAC or ANT to ADP and thus, enabling normal activity of the $\mathrm{F}_{0} \mathrm{~F}_{1}$-ATP synthase, maintaining the appropriate $\Delta \Psi \mathrm{m}$. In contrast, another study argued that BCL-2 maintains the $\Delta \Psi \mathrm{m}$ following death signals by inducing $\mathrm{H}^{+}$efflux from the mitochondria (Shimizu et al. 1998).

How are pro-apoptotic molecules working? As summarized, pro-apoptotic molecules can work by heterodimerizing with anti-apoptotic molecules to inhibit their function, although, others appear to be working more independently. Interestingly, yeast provide support for this independent action since expression of BAX in yeast causes an increase in $\Delta \Psi \mathrm{m}$ (Minn et al. 1999) and eventually cell death. Of note, yeast lack obvious orthologs of BCL-2 members or caspases. In addition, it was reported that yeast strains carrying mutations in $\mathrm{F}_{0} \mathrm{~F}_{1}$-ATP synthase or lacking the ANT are more resistant to BAX toxicity (Marzo et al. 1998; Matsuyama et al. 1998). In this setting the release of proteins from mitochondria (e.g., cytochrome $c$ ) would be a relatively late event that occurs indirectly as a result of rupturing the outer membrane. However, release of cytochrome $c$ has been demonstrated to occur independent of altered $\Delta \Psi \mathrm{m}$ arguing that cytochrome $c$ release may reflect a more specialized mechanism (Bossy-Wetzel et al. 1998).

\section{Downstream of mitochondria: important factors for cell execution}

What roles do mitochondria play in apoptosis? Clearly, one event is the release of pro-apoptotic molecules into the cytosol. Release of cytochrome $c$, which occurs following a variety of death stimuli (Liu et al. 1996; Kluck et al. 1997; Bossy-Wetzel et al. 1998), has been shown to activate Apaf-1, which in turn activates caspase-9 and caspase-3 (Li et al. 1997; Zou et al. 1997). In some cell types cytochrome $c$ is not released but goes through a conformational change that may still enable Apaf- 1 activation at the mitochondrial membrane (Jemmerson et al. 1999; Varkey et al. 1999). Recently, evidence has been presented that pro-caspase- 2 and pro-caspase- 9 are released from the mitochondria following PTP opening (Susin et al. 1999a). In addition, pro-caspase-3 appears to have both cytosolic and mitochondrial distributions (Mancini et al. 1998) and BCL-2 can regulate the activation of the mitochondrial pool (Krebs et al. 1999). Translocation of active caspases in the opposite direction (e.g., from the cytosol to mitochondria) has also been noted (Chandler et al. 1998). There is also emerging evidence for the existence of further tethering proteins such as Bap31 in the ER ( $\mathrm{Ng}$ et al. 1997), which bind both caspases and BCL-2 family members and may coordinate their activities at these sites. Thus, mitochondria and 
perhaps other organelles make substantial contributions to the effector phase of apoptosis.

\section{Caspase-independent pathways}

The importance of caspases in the apoptotic process is well established; however, following certain stimuli apoptosis proceeds in a caspase-independent fashion. Expression of BAX or BAK induces apoptosis in the presence of broad caspase inhibition (Xiang et al. 1996; McCarthy et al. 1997). Both can also induce mitochondrial dysfunction and kill yeast, which lack endogenous caspases (Greenhalf et al. 1996; Zha et al. 1996b; Ink et al. 1997). AIF, which is not a caspase and is released from the mitochondria during apoptosis, can induce apoptosis (Susin et al. 1999b). Of note, Ced-4, which is proposed to work solely through the activation of Ced-3, is also toxic to yeast (James et al. 1997) suggesting that Apaf-1 may possess caspase-independent activities as well.

\section{Mitochondria-dependent and mitochondria- independent pathways}

It is quite clear that some cell types rely on the 'apoptotic function' of mitochondria, whereas others do not. Some death stimuli induce death pathways that directly involve mitochondria whereas others do not. The bestcharacterized signal transduction pathways that mediate apoptosis are the cell surface receptors of the TNF family (Nagata 1997; Ashkenazi and Dixit 1998; Wallach et al. 1998). Engagement of TNF/Fas receptor leads to recruitment and activation of casapse- 8 , which in turn activates a downstream caspase pathway (Medema et al. 1997). Certain cell types (type II) require mitochondria, whereas others (type I) die without an apparent need for this organelle (Scaffidi et al. 1998). A cell-free system has indicated that caspase- 8 activates a mitochondria-dependent pathway that involves cytochrome $c$ as well as a mitochondrial-independent pathway (Kuwana et al. 1998). Recently, it has been demonstrated that Apaf-1 ${ }^{-/-}$and caspase- $9^{-/-}$T cells remain sensitive to Fas-induced killing (Hakem et al. 1998; Kuida et al. 1998; Yoshida et al. 1998). However, Fas-induced apoptosis was markedly reduced in Apaf-1 $1^{-/-}$embryonic fibroblasts (Cecconi et al. 1998) suggesting that the same death signal may be using different pathways in different cell types. The results in $\mathrm{T}$ cells indicate that the apoptotic function of mitochondria (at least the cytochrome $c$ release part) can be bypassed in these cells.

Other less defined pathways that lead to apoptosis are the ones initiated by chemicals or radiation. These pathways seem to rely on the apoptotic function of mitochondria, since Apaf-1 ${ }^{-/-}$and casapse- $9^{-/-}$cells are principally resistant to these death inducing agents (Cecconi et al. 1998; Hakem et al. 1998; Kuida et al. 1998; Yoshida et al. 1998). It was recently demonstrated that zVADfmk (Z-Val-Ala-Asp $\left.(\mathrm{OMe}) \mathrm{CH}_{2} \mathrm{~F}\right)$ inhibits the fall in $\Delta \Psi \mathrm{m}$ and cytochrome $c$ release following Fas treatment but not following chemical or radiation treatment (Sun et al. 1999).

\section{Pro-apoptotic BCL-2 members as sentinels for cellular damage}

Proteins that change location within cells and undergo post-translational modifications become candidates to interconnect cell biologic processes with proximal signal transduction. In that context, it is remarkable how many of the pro-death BCL-2 members demonstrate modifications and protein translocation upon receipt of a death stimulus. BAX dimerizes in response to survival factor deprivation, $\mathrm{BAD}$ is phosphorylated in response to factor stimulation or dephosphorylated by calcineurin in response to calcium elevations (Wang et al. 1999). BID is cleaved following $\mathrm{TNF} \alpha /$ Fas signaling and all three move to mitochondria. The pro-apoptotic Egl-1 of C. elegans links the common apoptotic pathway of CED-9, CED-4, and CED-3 with lineage-specific, cell-specification genes upstream. In that respect, the mammalian pro-apoptotic BCL-2 members occupy a similar functional position linking common and private pathways of apoptosis.

Finally, the existence of inactive conformers that must be activated by death signals plus the varied locations of pro-apoptotic molecules in viable cells suggests these members may serve as sentinels for cellular damage. These upstream BCL-2 family molecules may be strategically positioned to inventory cell damage at specific sites. In this model BIM would monitor microtubule function, BID would be on the lookout for minimal caspase- 8 activation, and BAX and BAD would patrol metabolic stress following loss of critical survival factors. This would be an attractive mechanism whereby a panoply of seemingly diverse injuries could rapidly converge on the common apoptotic pathway. The sudden exposure of a forbidden $\mathrm{BH} 3$ domain surface in response to select damage would enable cells to enter the physiologic apoptotic rather than necrotic pathway. This could prove to be a unified role, especially for the BH3domain-only subset of molecules.

\section{Acknowledgments}

A.G. was supported by a European Molecular Biology Organization fellowship and currently is supported by a fellowship from the Leukemia Society of America.

\section{References}

Adams, J.M. and S. Cory. 1998. The Bcl-2 protein family: Arbiters of cell survival. Science 281: 1322-1326.

Antonsson, B., F. Conti, A. Ciavatta, S. Montessuit, S. Lewis, I. Martinou, L. Bernasconi, A. Bernard, J.J. Mermod, G. Mazzei, K. Maundrell, F. Gambale, R. Sadoul, and J.C. Martinou. 1997. Inhibition of Bax channel-forming activity by Bcl-2. Science 277: 370-372.

Ashkenazi, A. and V.M. Dixit. 1998. Death receptors: Signaling and modulation. Science 281: 1305-1308.

Avdonin, V., J. Kasuya, M.A. Ciorba, B. Kaplan, T. Hoshi, and L. Iverson. 1998. Apoptotic proteins Reaper and Grim induce stable inactivation in voltage-gated $\mathrm{K}^{+}$channels. Proc. Natl. Acad. Sci. 95: 11703-11708. 
Blume-Jensen, P., R. Janknecht, and T. Hunter. 1998. The kit receptor promotes cell survival via activation of PI 3-kinase and subsequent Akt-mediated phosphorylation of Bad on Ser136. Curr. Biol. 8: 779-782.

Boise, L.H., A.J. Minn, P.J. Noel, C.H. June, M.A. Accavitti, T. Lindsten, and C.B. Thompson. 1995. CD28 costimulation can promote $T$ cell survival by enhancing the expression of Bcl-XL. Immunity 3: 87-98.

Bossy-Wetzel, E., D.D. Newmeyer, and D.R. Green. 1998. Mitochondrial cytochrome c release in apoptosis occurs upstream of DEVD-specific caspase activation and independently of mitochondrial transmembrane depolarization. EMBO I. 17: 37-49.

Brunet, A., A. Bonni, M.J. Zigmond, M.Z. Lin, P. Juo, L.S. Hu, M.J. Anderson, K.C. Arden, J. Blenis, and M.E. Greenberg. 1999. Akt promotes cell survival by phosphorylating and inhibiting a Forkhead transcription factor. Cell 96: 857-868.

Cardone, M.H., N. Roy, H.R. Stennicke, G.S. Salvesen, T.F. Franke, E. Stanbridge, S. Frisch, and J.C. Reed. 1998. Regulation of cell death protease caspase-9 by phosphorylation. Science 282: 1318-1321.

Cecconi, F., G. Alvarez-Bolado, B.I. Meyer, K.A. Roth, and P. Gruss. 1998. Apaf1 (CED-4 homolog) regulates programmed cell death in mammalian development. Cell 94: 727-737.

Chandler, J.M., G.M. Cohen, and M. MacFarlane. 1998. Different subcellular distribution of caspase-3 and caspase- 7 following Fas-induced apoptosis in mouse liver. J. Biol. Chem. 273: 10815-10818.

Chang, B.S., A.J. Minn, S.W. Muchmore, S.W. Fesik, and C.B. Thompson. 1997. Identification of a novel regulatory domain in Bcl-X(L) and Bcl-2. EMBO J. 16: 968-977.

Cheng, E.H., B. Levine, L.H. Boise, C.B. Thompson, and J.M. Hardwick. 1996. Bax-independent inhibition of apoptosis by Bcl-XL. Nature 379: 554-556.

Cheng, E.H., D.G. Kirsch, R.J. Clem, R. Ravi, M.B. Kastan, A. Bedi, K. Ueno, and J.M. Hardwick. 1997. Conversion of Bcl-2 to a Bax-like death effector by caspases. Science 278: 1966 1968.

Chou, J.J., H. Li, G.S. Salvesen, J. Yuan, and G. Wagner. 1999. Solution structure of BID, an intracellular amplifier of apoptotic signaling. Cell 96: 615-624.

Clem, R.J., E.H. Cheng, C.L. Karp, D.G. Kirsch, K. Ueno, A. Takahashi, M.B. Kastan, D.E. Griffin, W.C. Earnshaw, M.A. Veliuona, and J.M. Hardwick. 1998. Modulation of cell death by Bcl-XL through caspase interaction. Proc. Natl. Acad. Sci. 95: 554-559.

Conradt, B. and H.R. Horvitz. 1998. The C. elegans protein EGL-1 is required for programmed cell death and interacts with the Bcl-2-like protein CED-9. Cell 93: 519-529.

Darnell, J.E., H.F. Lodish, and D. Baltimore. 1990. Molecular Cell Biology. W.H. Freeman, New York, N.Y.

Datta, S.R., H. Dudek, X. Tao, S. Masters, H. Fu, Y. Gotoh, and M.E. Greenberg. 1997. Akt phosphorylation of BAD couples survival signals to the cell-intrinsic death machinery. Cell 91: 231-241.

de Jong, D., F.A. Prins, D.Y. Mason, J.C. Reed, G.B. van Ommen, and P.M. Kluin. 1994. Subcellular localization of the bcl-2 protein in malignant and normal lymphoid cells. Cancer Res. 54: 256-260.

del Peso, L., M. Gonzalez-Garcia, C. Page, R. Herrera, and G. Nunez. 1997. Interleukin-3-induced phosphorylation of BAD through the protein kinase Akt. Science 278: 687-689.

Desagher, S., A. Osen-Sand, A. Nichols, R. Eskes, S. Montessuit, S. Lauper, K. Maundrell, B. Antonsson, and J.C. Martinou. 1999. Bid-induced conformational change of Bax is responsible for mitochondrial cytochrome c release during apopto- sis. J. Cell Biol. 144: 891-901.

Eskes, R., B. Antonsson, A. Osen-Sand, S. Montessuit, C. Richter, R. Sadoul, G. Mazzei, A. Nichols, and J.C. Martinou. 1998. Bax-induced cytochrome C release from mitochondria is independent of the permeability transition pore but highly dependent on $\mathrm{Mg}^{2+}$ ions. J. Cell Biol. 143: 217-224.

Finucane, D.M., E. Bossy-Wetzel, N.J. Waterhouse, T.G. Cotter, and D.R. Green. 1999. Bax-induced caspase activation and apoptosis via cytochrome c release from mitochondria is inhibitable by Bcl-XL. J. Biol. Chem. 274: 2225-2233.

Goping, I.S., A. Gross, J.N. Lavoie, M. Nguyen, R. Jemmerson, K. Roth, S.J. Korsmeyer, and G.C. Shore. 1998. Regulated targeting of BAX to mitochondria. J. Cell Biol. 143: 207-215.

Grandgirard, D., E. Studer, L. Monney, T. Belser, I. Fellay, C. Borner, and M.R. Michel. 1998. Alphaviruses induce apoptosis in Bcl-2-overexpressing cells: evidence for a caspasemediated, proteolytic inactivation of Bcl-2. EMBO $I$. 17: $1268-1278$.

Green, D. and G. Kroemer. 1998. The central executioners of apoptosis: caspases or mitochondria? Trends Cell Biol. 8: $267-271$.

Green, D.R. and J.C. Reed. 1998. Mitochondria and apoptosis. Science 281: 1309-1312.

Greenhalf, W., C. Stephan, and B. Chaudhuri. 1996. Role of mitochondria and C-terminal membrane anchor of Bcl-2 in Bax induced growth arrest and mortality in Saccharomyces cerevisiae. FEBS Lett. 380: 169-175.

Griffiths, G.J., L. Dubrez, C.P. Morgan, N.A. Jones, J. Whitehouse, B.M. Corfe, C. Dive, and J.A. Hickman. 1999. Cell damage-induced conformational changes of the pro-apoptotic protein Bak in vivo precede the onset of apoptosis. $J$. Cell Biol. 144: 903-914.

Gross, A., J. Jockel, M.C. Wei, and S.J. Korsmeyer. 1998. Enforced dimerization of BAX results in its translocation, mitochondrial dysfunction and apoptosis. EMBO J. 17: 3878 3885.

Gross, A., X.M. Yin, K. Wang, M.C. Wei, J. Jockel, C. Milliman, H. Erdjument-Bromage, P. Tempst, and S.J. Korsmeyer. 1999. Caspase cleaved BID targets mitochondria and is required for cytochrome c release, while BCL-XL prevents this release but not tumor necrosis factor-R1/Fas death. J. Biol. Chem. 274: 1156-1163.

Grumont, R.J., I.J. Rourke, and S. Gerondakis. 1999. Rel-dependent induction of A1 transcription is required to protect $\mathrm{B}$ cells from antigen receptor ligation-induced apoptosis. Genes \& Dev. 13: 400-411.

Hakem, R., A. Hakem, G.S. Duncan, J.T. Henderson, M. Woo, M.S. Soengas, A. Elia, J.L. de la Pompa, D. Kagi, W. Khoo, J. Potter, R. Yoshida, S.A. Kaufman, S.W. Lowe, J.M. Penninger, and T.W. Mak. 1998. Differential requirement for caspase 9 in apoptotic pathways in vivo. Cell 94: 339-352.

Haldar, S., N. Jena, and C.M. Croce. 1995. Inactivation of Bcl-2 by phosphorylation. Proc. Natl. Acad. Sci. 92: 4507-4511.

Han, Z., K. Bhalla, P. Pantazis, E.A. Hendrickson, and J.H. Wyche. 1999. Cif (Cytochrome c efflux-inducing factor) activity is regulated by Bcl-2 and caspases and correlates with the activation of Bid. Mol. Cell. Biol. 19: 1381-1389.

Harada, H., B. Becknell, M. Wilm, M. Mann, L.J. Huang, S.S. Taylor, J.D. Scott, and S.J. Korsmeyer. 1999. Phosphorylation and inactivation of $\mathrm{BAD}$ by mitochondria-anchored protein kinase A. Mol. Cell 3: 413-422.

Hengartner, M.O. 1997. Apoptosis. CED-4 is a stranger no more. Nature 388: 714-715.

Hockenbery, D., G. Nunez, C. Milliman, R.D. Schreiber, and S.J. Korsmeyer. 1990. Bcl-2 is an inner mitochondrial membrane protein that blocks programmed cell death. Nature 
348: 334-336.

Hsu, Y.T. and R.J. Youle. 1997. Nonionic detergents induce dimerization among members of the Bcl-2 family. J. Biol. Chem. 272: 13829-13834.

Hsu, Y.T., K.G. Wolter, and R.J. Youle. 1997. Cytosol-to-membrane redistribution of $\mathrm{Bax}$ and $\mathrm{Bcl}-\mathrm{X}(\mathrm{L})$ during apoptosis. Proc. Nat1. Acad. Sci. 94: 3668-3672.

Hu, Y., M.A. Benedict, D. Wu, N. Inohara, and G. Nunez. 1998. Bcl-XL interacts with Apaf-1 and inhibits Apaf-1-dependent caspase-9 activation. Proc. Natl. Acad. Sci. 95: 4386-4391.

Ink, B., M. Zornig, B. Baum, N. Hajibagheri, C. James, T. Chittenden, and G. Evan. 1997. Human Bak induces cell death in Schizosaccharomyces pombe with morphological changes similar to those with apoptosis in mammalian cells. Mol. Cell. Biol. 17: 2468-2474.

Inohara, N., L. Ding, S. Chen, and G. Nunez. 1997. harakiri, a novel regulator of cell death, encodes a protein that activates apoptosis and interacts selectively with survival-promoting proteins Bcl-2 and Bcl-X(L). EMBO J. 16: 1686-1694.

Inohara, N., T.S. Gourley, R. Carrio, M. Muniz, J. Merino, I. Carcia, T. Koseki, Y. Hu, S. Chen, and G. Nunez. 1998. Diva, a-Bc1-2 homologue that binds directly to Apaf-1 and induces BH3-independent cell death. J. Biol. Chem. 273: 3247932486.

Ito, T., X. Deng, B. Carr, and W.S. May. 1997. Bcl-2 phosphorylation required for anti-apoptosis function. J. Biol. Chem. 272: 11671-11673.

James, C., S. Gschmeissner, A. Fraser, and G.I. Evan. 1997. CED-4 induces chromatin condensation in Schizosaccharomyces pombe and is inhibited by direct physical association with CED-9. Curr. Biol. 7: 246-252.

Jemmerson, R., J. Liu, D. Hausauer, K.P. Lam, A. Mondino, and R.D. Nelson. 1999. A conformational change in cytochrome c of apoptotic and necrotic cells is detected by monoclonal antibody binding and mimicked by association of the native antigen with synthetic phospholipid vesicles. Biochemistry 38: 3599-3609.

Jurgensmeier, J.M., Z. Xie, Q. Deveraux, L. Ellerby, D. Bredesen, and J.C. Reed. 1998. Bax directly induces release of cytochrome c from isolated mitochondria. Proc. Natl. Acad. Sci. 95: 4997-5002.

Kelekar, A. and C.B. Thompson. 1998. Bcl-2-family proteins: the role of the BH3 domain in apoptosis. Trends Cell Biol. 8: 324-330.

Kelekar, A., B.S. Chang, J.E. Harlan, S.W. Fesik, and C.B. Thompson. 1997. Bad is a $\mathrm{BH} 3$ domain-containing protein that forms an inactivating dimer with Bcl-XL. Mol. Cell. Biol. 17: 7040-7046.

Kluck, R.M., E. Bossy-Wetzel, D.R. Green, and D.D. Newmeyer. 1997. The release of cytochrome c from mitochondria: A primary site for $\mathrm{Bcl}-2$ regulation of apoptosis. Science 275: 1132-1136.

Knudson, C.M. and S.J. Korsmeyer. 1997. Bcl-2 and Bax function independently to regulate cell death. Nat. Genet. 16: 358 363.

Kozopas, K.M., T. Yang, H.L. Buchan, P. Zhou, and R.W. Craig. 1993. MCL1, a gene expressed in programmed myeloid cell differentiation, has sequence similarity to BCL2. Proc. Nat1. Acad. Sci. 90: 3516-3520.

Krajewski, S., S. Tanaka, S. Takayama, M.J. Schibler, W. Fenton, and J.C. Reed. 1993. Investigation of the subcellular distribution of the bcl-2 oncoprotein: Residence in the nuclear envelope, endoplasmic reticulum, and outer mitochondrial membranes. Cancer Res. 53: 4701-4714.

Krebs, J.F., R.C. Armstrong, A. Srinivasan, T. Aja, A.M. Wong, A. Aboy, R. Sayers, B. Pham, T. Vu, K. Hoang, D.S.
Karanewsky, C. Leist, A. Schmitz, J.C. Wu, K.J. Tomaselli, and L.C. Fritz. 1999. Activation of membrane-associated procaspase-3 is regulated by Bcl-2. J. Cell Biol. 144: 915-926.

Kuida, K., T.F. Haydar, C.Y. Kuan, Y. Gu, C. Taya, H. Karasuyama, M.S. Su, P. Rakic, and R.A. Flavell. 1998. Reduced apoptosis and cytochrome c-mediated caspase activation in mice lacking caspase 9. Cell 94: 325-337.

Kuwana, T., J.J. Smith, M. Muzio, V. Dixit, D.D. Newmeyer, and S. Kornbluth. 1998. Apoptosis induction by caspase- 8 is amplified through the mitochondrial release of cytochrome c. J. Biol. Chem. 273: 16589-16594.

Lam, M., M.B. Bhat, G. Nunez, J. Ma, and C.W. Distelhorst. 1998. Regulation of Bcl-xl channel activity by calcium. J. Biol. Chem. 273: 17307-17310.

Lewis, S., S.S. Bethell, S. Patel, J.C. Martinou, and B. Antonsson. 1998. Purification and biochemical properties of soluble recombinant human Bax. Protein Exp. Purif. 13: 120-126.

Li, H., H. Zhu, C.J. Xu, and J. Yuan. 1998. Cleavage of BID by caspase 8 mediates the mitochondrial damage in the Fas pathway of apoptosis. Cell 94: 491-501.

Li, P., D. Nijhawan, I. Budihardjo, S.M. Srinivasula, M. Ahmad, E.S. Alnemri, and X. Wang. 1997. Cytochrome c and dATPdependent formation of Apaf-1/caspase-9 complex initiates an apoptotic protease cascade. Cell 91: 479-489.

Lin, E.Y., A. Orlofsky, M.S. Berger, and M.B. Prystowsky. 1993. Characterization of A1, a novel hemopoietic-specific earlyresponse gene with sequence similarity to bcl-2. J. Immunol. 151: 1979-1988.

Liu, X., C.N. Kim, J. Yang, R. Jemmerson, and X. Wang. 1996. Induction of apoptotic program in cell-free extracts: requirement for dATP and cytochrome c. Cell 86: 147-157.

Luo, X., I. Budihardjo, H. Zou, C. Slaughter, and X. Wang. 1998. $\mathrm{Bid}, \mathrm{a} \mathrm{Bcl} 2$ interacting protein, mediates cytochrome $\mathrm{c}$ release from mitochondria in response to activation of cell surface death receptors. Cell 94: 481-490.

Mahajan, N.P., K. Linder, G. Berry, G.W. Gordon, R. Heim, and B. Herman. 1998. Bcl-2 and Bax interactions in mitochondria probed with green fluorescent protein and fluorescence resonance energy transfer. Nat. Biotechnol. 16: 547-552.

Mancini, M., D.W. Nicholson, S. Roy, N.A. Thornberry, E.P. Peterson, L.A. Casciola-Rosen, and A. Rosen. 1998. The caspase-3 precursor has a cytosolic and mitochondrial distribution: implications for apoptotic signaling. J. Cell Biol. 140: $1485-1495$.

Marzo, I., C. Brenner, N. Zamzami, J.M. Jurgensmeier, S.A. Susin, H.L. Vieira, M.C. Prevost, Z. Xie, S. Matsuyama, J.C. Reed, and G. Kroemer. 1998. Bax and adenine nucleotide translocator cooperate in the mitochondrial control of apoptosis. Science 281: 2027-2031.

Matsuyama, S., Q. Xu, J. Velours, and J.C. Reed. 1998. The Mitochondrial $\mathrm{F}_{0} \mathrm{~F}_{1}$-ATPase proton pump is required for function of the proapoptotic protein Bax in yeast and mammalian cells. Mol. Cell 1: 327-336.

McCarthy, N.J., M.K. Whyte, C.S. Gilbert, and G.I. Evan. 1997. Inhibition of Ced-3/ICE-related proteases does not prevent cell death induced by oncogenes, DNA damage, or the Bcl-2 homologue Bak. J. Cell Biol. 136: 215-227.

McDonnell, J.M., D. Fushman, C.L. Milliman, S.J. Korsmeyer, and D. Cowburn. 1999. Solution structure of the proapoptotic molecule BID: A structural basis for apoptotic agonists and antagonists. Cell 96: 625-634.

Medema, J.P., C. Scaffidi, F.C. Kischkel, A. Shevchenko, M. Mann, P.H. Krammer, and M.E. Peter. 1997. FLICE is activated by association with the CD95 death-inducing signaling complex (DISC). EMBO J. 16: 2794-2804.

Minn, A.J., P. Velez, S.L. Schendel, H. Liang, S.W. Muchmore, 
S.W. Fesik, M. Fill, and C.B. Thompson. 1997. Bcl-x(L) forms an ion channel in synthetic lipid membranes. Nature 385: 353-357.

Minn, A.J., C.S. Kettlun, H. Liang, A. Kelekar, M.G. Vander Heiden, B.S. Chang, S.W. Fesik, M. Fill, and C.B. Thompson. 1999. Bcl-xL regulates apoptosis by heterodimerization-dependent and -independent mechanisms. EMBO J. 18: 632643.

Miyashita, T. and J.C. Reed. 1995. Tumor suppressor p53 is a direct transcriptional activator of the human bax gene. Cell 80: 293-299.

Muchmore, S.W., M. Sattler, H. Liang, R.P. Meadows, J.E. Harlan, H.S. Yoon, D. Nettesheim, B.S. Chang, C.B. Thompson, S.L. Wong, S.L. Ng, and S.W. Fesik. 1996. X-ray and NMR structure of human Bcl-xL, an inhibitor of programmed cell death. Nature 381: 335-341.

Nagata, S. 1997. Apoptosis by death factor. Cell 88: 355-365.

Narita, M., S. Shimizu, T. Ito, T. Chittenden, R.J. Lutz, H. Matsuda, and Y. Tsujimoto. 1998. Bax interacts with the permeability transition pore to induce permeability transition and cytochrome c release in isolated mitochondria. Proc. Natl. Acad. Sci. 95: 14681-14686.

Ng, F.W., M. Nguyen, T. Kwan, P.E. Branton, D.W. Nicholson, J.A. Cromlish, and G.C. Shore. 1997. p28 Bap31, a Bcl-2/Bcl$\mathrm{XL}$ - and procaspase-8-associated protein in the endoplasmic reticulum. J. Cell Biol. 139: 327-338.

Nguyen, M., D.G. Millar, V.W. Yong, S.J. Korsmeyer, and G.C. Shore. 1993. Targeting of Bcl-2 to the mitochondrial outer membrane by a $\mathrm{COOH}$-terminal signal anchor sequence. $J$. Biol. Chem. 268: 25265-25268.

Nicholls, A., K.A. Sharp, and B. Honig. 1991. Protein folding and association: Insights from the interfacial and thermodynamic properties of hydrocarbons. Proteins 11: 281-296.

Oltvai, Z.N., C.L. Milliman, and S.J. Korsmeyer. 1993. Bcl-2 heterodimerizes in vivo with a conserved homolog, Bax, that accelerates programmed cell death. Cell 74: 609-619.

Ottilie, S., J.L. Diaz, W. Horne, J. Chang, Y. Wang, G. Wilson, S. Chang, S. Weeks, L.C. Fritz, and T. Oltersdorf. 1997. Dimerization properties of human BAD. Identification of a $\mathrm{BH}-3$ domain and analysis of its binding to mutant BCL-2 and BCL-XL proteins. J. Biol. Chem. 272: 30866-30872.

Pan, G., K. O'Rourke, and V.M. Dixit. 1998. Caspase-9, Bcl-XL, and Apaf-1 form a ternary complex. I. Biol. Chem. 273: $5841-5845$.

Pastorino, J.G., S.T. Chen, M. Tafani, J.W. Snyder, and J.L. Farber. 1998. The overexpression of Bax produces cell death upon induction of the mitochondrial permeability transition. J. Biol. Chem. 273: 7770-7775.

Poommipanit, P.B., B. Chen, and Z.N. Oltvai. 1999. Interleukin-3 induces the phosphorylation of a distinct fraction of bcl- 2. J. Biol. Chem. 274: 1033-1039.

Puthalakath, H., D.C. Huang, L.A. O'Reilly, S.M. King, and A. Strasser. 1999. The proapoptotic activity of the Bcl-2 family member Bim is regulated by interaction with the dynein motor complex. Mol. Cell 3: 287-296.

Reed, J.C. 1998. Bcl-2 family proteins. Oncogene 17: 3225-3236.

Sattler, M., H. Liang, D. Nettesheim, R.P. Meadows, J.E. Harlan, M. Eberstadt, H.S. Yoon, S.B. Shuker, B.S. Chang, A.J. Minn, C.B. Thompson, and S.W. Fesik. 1997. Structure of Bcl-xLBak peptide complex: recognition between regulators of apoptosis. Science 275: 983-986.

Scaffidi, C., S. Fulda, A. Srinivasan, C. Friesen, F. Li, K.J. Tomaselli, K.M. Debatin, P.H. Krammer, and M.E. Peter. 1998. Two CD95 (APO-1/Fas) signaling pathways. EMBO $J$. 17: 1675-1687.

Schendel, S.L., Z. Xie, M.O. Montal, S. Matsuyama, M. Montal, and J.C. Reed. 1997. Channel formation by antiapoptotic protein Bcl-2. Proc. Natl. Acad. Sci. 94: 5113-5118.

Schendel, S.L., M. Montal, and J.C. Reed. 1998. Bcl-2 family proteins as ion-channels. Cell Death Differ. 5: 372-380.

Schlesinger, P.H., A. Gross, X.M. Yin, K. Yamamoto, M. Saito, G. Waksman, and S.J. Korsmeyer. 1997. Comparison of the ion channel characteristics of proapoptotic BAX and antiapoptotic BCL-2. Proc. Nat1. Acad. Sci. 94: 11357-11362.

Sedlak, T.W., Z.N. Oltvai, E. Yang, K. Wang, L.H. Boise, C.B. Thompson, and S.J. Korsmeyer. 1995. Multiple Bcl-2 family members demonstrate selective dimerizations with Bax. Proc. Natl. Acad. Sci. 92: 7834-7838.

Shimizu, S., Y. Eguchi, W. Kamiike, Y. Funahashi, A. Mignon, V. Lacronique, H. Matsuda, and Y. Tsujimoto. 1998. Bcl-2 prevents apoptotic mitochondrial dysfunction by regulating proton flux. Proc. Nat1. Acad. Sci. 95: 1455-1459.

Single, B., M. Leist, and P. Nicotera. 1998. Simultaneous release of adenylate kinase and cytochrome c in cell death. Cell Death Differ. 5: 1001-1003.

Song, Q., Y. Kuang, V.M. Dixit, and C. Vincenz. 1999, Boo, a novel negative regulator of cell death, interacts with Apaf-1. EMBO J. 18: 167-178.

Sun, X.M., M. MacFarlane, J. Zhuang, B.B. Wolf, D.R. Green, and G.M. Cohen. 1999. Distinct caspase cascades are initiated in receptor-mediated and chemical-induced apoptosis. $J$. Biol. Chem. 274: 5053-5060.

Susin, S.A., H.K. Lorenzo, N. Zamzami, I. Marzo, C. Brenner, N. Larochette, M.C. Prevost, P.M. Alzari, and G. Kroemer. 1999a. Mitochondrial release of caspase-2 and -9 during the apoptotic process. J. Exp. Med. 189: 381-394.

Susin, S.A., H.K. Lorenzo, N. Zamzami, I. Marzo, B.E. Snow, G.M. Brothers, J. Mangion, E. Jacotot, P. Costantini, M. Loeffler, N. Larochette, D.R. Goodlett, R. Aebersold, D.P. Siderovski, J.M. Penninger, and G. Kroemer. 1999b. Molecular characterization of mitochondrial apoptosis-inducing factor. Nature 397: 441-446.

Thornberry, N.A. and Y. Lazebnik. 1998. Caspases: Enemies within. Science 281: 1312-1316.

Vander Heiden, M.G., N.S. Chandel, E.K. Williamson, P.T. Schumacker, and C.B. Thompson. 1997. Bcl-xL regulates the membrane potential and volume homeostasis of mitochondria. Cell 91: 627-637.

Vander Heiden, M.G., N.S. Chandel, P.T. Schumacker, and C.B. Thompson. 1999. Bcl-xL prevents cell death following growth factor withdrawal by facilitating mitochondrial ATP/ADP exchange. Mol. Cell 3: 159-167.

Varkey, J., P. Chen, R. Jemmerson, and J.M. Abrams. 1999. Altered cytochrome c display precedes apoptotic cell death in Drosophila. J. Cell Biol. 144: 701-710.

Vaux, D.L. and S.J. Korsmeyer. 1999. Cell death in development. Cell 96: 245-254.

von Freeden-Jeffry, U., N. Solvason, M. Howard, and R. Murray. 1997. The earliest T lineage-committed cells depend on IL-7 for Bcl-2 expression and normal cell cycle progression. Immunity 7: 147-154

Wallach, D., A.V. Kovalenko, E.E. Varfolomeev, and M.P. Boldin. 1998. Death-inducing functions of ligands of the tumor necrosis factor family: a Sanhedrin verdict. Curr. Opin. Immunol. 10: 279-288.

Wang, H., N. Pathan, I.M. Ethell, S. Krajewski, Y. Yamaguchi, F. Shibasaki, F. McKeon, T. Bobo, T.F. Franke, and J.C. Reed. 1999. $\mathrm{Ca}^{2+}$-induced apoptosis through calcineurin dephosphorylation of BAD. Science 284: 339-343.

Wang, K., X.M. Yin, D.T. Chao, C.L. Milliman, and S.J. Korsmeyer. 1996. BID: A novel BH3 domain-only death agonist. Genes \& Dev. 10: 2859-2869. 
Wang, K., A. Gross, G. Waksman, and S.J. Korsmeyer. 1998. Mutagenesis of the BH3 domain of BAX identifies residues critical for dimerization and killing. Mol. Cell Biol. 18: 6083-6089.

Wolter, K.G., Y.T. Hsu, C.L. Smith, A. Nechushtan, X.G. Xi, and R.J. Youle. 1997. Movement of Bax from the cytosol to mitochondria during apoptosis. J. Cell Biol. 139: 1281-1292.

Xiang, J., D.T. Chao, and S.J. Korsmeyer. 1996. BAX-induced cell death may not require interleukin 1 beta-converting enzyme-like proteases. Proc. Natl. Acad. Sci. 93: 14559-14563.

Yoshida, H., Y.Y. Kong, R. Yoshida, A.J. Elia, A. Hakem, R. Hakem, J.M. Penninger, and T.W. Mak. 1998. Apaf1 is required for mitochondrial pathways of apoptosis and brain development. Cell 94: 739-750.

Zamzami, N., C. Brenner, I. Marzo, S.A. Susin, and G. Kroemer. 1998. Subcellular and submitochondrial mode of action of Bcl-2-like oncoproteins. Oncogene 16: 2265-2282.

Zha, H., C. Aime-Sempe, T. Sato, and J.C. Reed. 1996a. Proapoptotic protein Bax heterodimerizes with Bcl-2 and homodimerizes with Bax via a novel domain (BH3) distinct from BH1 and BH2. J. Biol. Chem. 271: 7440-7444.

Zha, H., H.A. Fisk, M.P. Yaffe, N. Mahajan, B. Herman, and J.C. Reed. 1996b. Structure-function comparisons of the proapoptotic protein Bax in yeast and mammalian cells. Mol. Cell Biol. 16: 6494-6508.

Zha, J., H. Harada, E. Yang, J. Jockel, and S.J. Korsmeyer. 1996c. Serine phosphorylation of death agonist BAD in response to survival factor results in binding to 14-3-3 not BCL-X(L). Cell 87: 619-628.

Zha, J., H. Harada, K. Osipov, J. Jockel, G. Waksman, and S.J. Korsmeyer. 1997. BH3 domain of BAD is required for heterodimerization with BCL-XL and pro-apoptotic activity. $J$. Biol. Chem. 272: 24101-24104.

Zhu, W., A. Cowie, G.W. Wasfy, L.Z. Penn, B. Leber, and D.W. Andrews. 1996. Bcl-2 mutants with restricted subcellular location reveal spatially distinct pathways for apoptosis in different cell types. EMBO J. 15: 4130-4141.

Zong, W.X., L.C. Edelstein, C. Chen, J. Bash, and C. Gelinas. 1999. The prosurvival Bcl-2 homolog Bfl-1/Al is a direct transcriptional target of NF-кB that blocks TNF $\alpha$-induced apoptosis. Genes \& Dev. 13: 382-387.

Zoratti, M. and I. Szabo. 1995. The mitochondrial permeability transition. Biochim. Biophys. Acta 1241: 139-176.

Zou, H., W.J. Henzel, X. Liu, A. Lutschg, and X. Wang. 1997. Apaf-1, a human protein homologous to C. elegans CED-4, participates in cytochrome c-dependent activation of caspase-3. Cell 90: 405-413. 


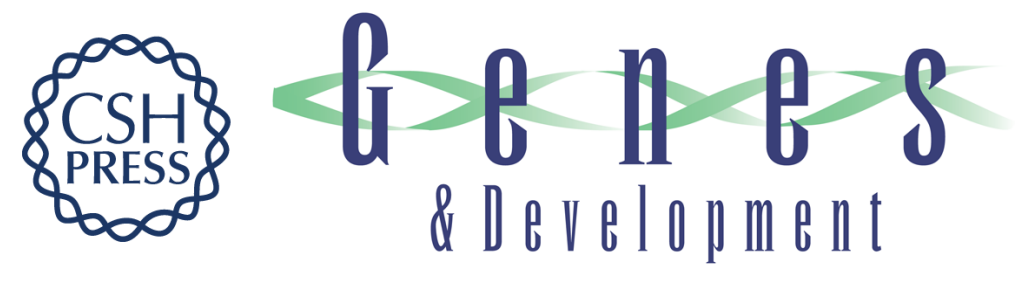

\section{BCL-2 family members and the mitochondria in apoptosis}

Atan Gross, James M. McDonnell and Stanley J. Korsmeyer

Genes Dev. 1999, 13:

References This article cites 121 articles, 72 of which can be accessed free at: http://genesdev.cshlp.org/content/13/15/1899.full.html\#ref-list-1

License

Email Alerting

Receive free email alerts when new articles cite this article - sign up in the box at the top Service right corner of the article or click here.

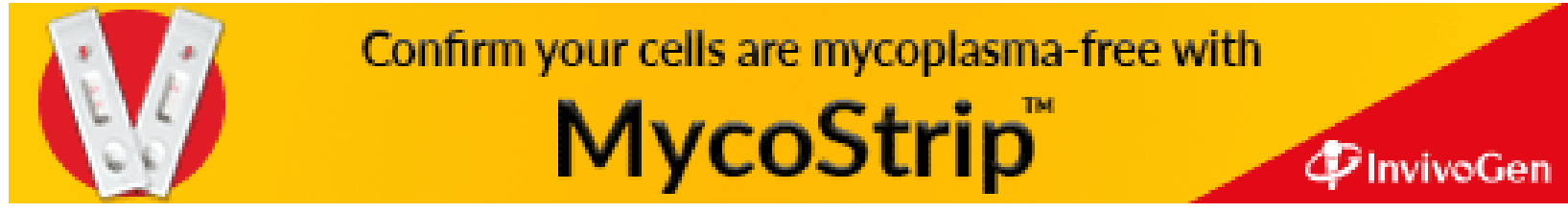

